\title{
PROF. DR. BOJAN ČOP
}

Dieser Band ist dem Indogermanisten Bojan Čop anläßlich seines 70. Geburtstags am 23. Mai 1993 gewidmet. Mit der nachstehenden, viel zu knappen Würdigung unseres bedeutendsten noch forschenden Vertreters der historischen Sprachwissenschaft verneigen wir uns - Fachkollegen wie Interessenten - vor einer großen Leistung.

Der Jubilar studierte und habilitierte sich an der Universität Ljubljana mit der Habilschrift: "Beitrag zur Geschichte der labialen Suffixe in indogermanischen Sprachen”. Seit 1947 ist er an der Philosophischen Fakultät in Ljubljana tätig, in den letzten Jahren allerdings noch als Emeritus, vordem 20 Jahre auch als Vorstand des Instituts für vergleichende und allgemeine Sprachwissenschaft und Orientalistik, wo er lehrte. 1972 wurde er korrespondierendes Mitglied, 1976 ordentliches Mitglied der Slowenischen Akademie der Wissenschaften und Künste in Ljubljana. Für eine seiner Monographien wurde an Prof. Čop 1976 der slowenische Preis der Wissenschaft vergeben und 1990 wurde ihm auch der größere Preis für seine wissenschaftliche Tätigkeit in toto zuteil. 1991 erteilte die Universität Ljubljana ihm den Ehrentitel Emeritus.

Prof. Čop publiziert seit 1952. Alle seine Arbeiten liegen im Bereich der vergleichenden Sprachwissenschaft, alles in allem sieben Bücher und etwa siebzig Studien in Zeitschriften, so in der Zeitschrift für vergleichende Sprachforschung, in den Indogermanischen Forschungen (Berlin), in Orbis (Louvain), Revue hittite et asianique (Paris), Acta linguistica Academiae scientiarum Hungaricae (Budapest), Die Sprache (Wiesbaden-Wien), Ural-altaische Jahrbücher (Wiesbaden).

Prof. Čop forscht viel in anatolischen Sprachen, besonders im Hetitischen und Luwischen. Gerade Arbeiten in diesem Bereich haben ihm schon in den frühen fünfziger Jahren den Weg in die sprachwissenschaftlichen Zeitschriften gebahnt. Der zweite Bereich dieser Art ist die Mykenologie. Die damals neudechiffrierten mykenischen Inschriften nutzend, leistete Prof. Čop seinen Beitrag zum Studium der Mykenologie im engeren Sinn und des Urgriechischen. Des weiteren widmet sich Prof. Čop etymologischen Studien. Darin hat er sich auf baltoslawische Etymologien konzentriert, vor allem auf allgemeinslawische Lexeme unklaren Ursprungs und auf slowenische und kroatische Archaismen. Seine weiteren etymologischen Studien betreffen u.a. indo-iranische, tocharische und armenische Lexeme. Neben den Etymologien behandelte Prof. Čop manche grammatische Erscheinung der genannten und anderen indogermanischen Sprachen. Prof. Čop hat italogriechische Isoglossen im Hinblick auf die Entwicklung der alten Balkansprachen untersucht und dadurch die Vorgeschichte der alten Balkansprachen beleuchtet. 
Einen Großteil seiner Kraft widmet Prof. Čop der sog. indo-uralischen Theorie. Diese untersucht die möglichen genetischen Beziehungen des Urindogermanischen, der ugro-finnischen und der übrigen uralischen Sprachen mit der Absicht, mithilfe der vergleichenden Methode den gemeinsamen Ahnen der indogermanischen und der uralischen Sprachen zu rekonstruieren, natürlich um möglicherweise Erklärungen für Aspekte der ältesten Sprachzustände des Urindogermanischen und des Ururalischen zu finden. Prof. Čop nutzte in diesen seiner Arbeiten den Wissensstand über die anatolischen Sprachen, des weiteren über die Laryngaltheorie sowie seine und die Ansichten anderer über die Struktur der indogermanischen Wurzel. Prof. Čop behandelte die Lautlehre der Suffixe und der lexikalischen Basen sowie die Morphologie. Aus seiner Feder ist die umfangreiche und noch nicht abgeschlossene Serie Indouralica entstanden. Prof. Čop ist zwar nicht der Urheber der indo-uralischen Theorie (diese Ehre fällt wahrscheinlich dem großen dänischen Sprachwissenschaftler Holger Pedersen zu), aber er ist jedenfalls bisher ihr weiterweisender und originellster Vertreter, gleichzeitig außerordentlich vorsichtig und streng in seiner konsequenten Anwendung der vergleichenden Methode, so wie sie in der Indogermanistik geübt wird. Man kann sagen, daß die indouralische Theorie mit den Forschungen von Prof. Čop in der historischen Sprachwissenschaft einen festen Platz erworben hat.

Als opferwilliger Universitätslehrer hat sich der Jubilar eine Reihe von jungen Sprachwissenschaftlern erzogen, von welchen einige schon breitere Anerkennung erfahren haben. Er iniziierte die Buchserie Series comparativa, die seinem Institut lange Jahre den Publikationsaustausch mit dem Ausland ermöglichte. Er ist auch Mitglied der Redaktion der Zeitschrift Linguistica (Ljubljana) und ihr Mitarbeiter von Anbeginn.

Prof. Čop ist international bekannt und zählt zu den hervorragendsten slowenischen Sprachwissenschaftlern. Hier ist es angebracht, besonders seine Bedeutung für die slowenische Sprachwissenschaft hervorzuheben: mit seinen schon erwähnten etymologischen Studien zu den alten indogermanischen Sprachen, namentlich zu den balto-slawischen, und mit seinen Untersuchungen verschiedener grammatischer Erscheinungen der einzelnen indogermanischen Sprachen und der Ursprachen hat Prof. Čop viele Aspekte des Altererbten im slowenischen Wortschatz sowie auch in der slowenischen Lautlehre und Morphologie beleuchtet bzw. auf historisch fundierte Weise erklärt. 